\title{
Review
}

\section{The role of hippocampal adult neurogenesis in methamphetamine addiction}

\author{
Yoshio Takashima and Chitra D. Mandyam* \\ Department of Anesthesiology, University of California San Diego, VA San Diego Healthcare System, \\ San Diego, CA, USA
}

\begin{abstract}
One of the consequences of chronic methamphetamine (Meth) abuse and Meth addiction is impaired hippocampal function which plays a critical role in enhanced propensity for relapse. This impairment is predicted by alterations in hippocampal neurogenesis, structural- and functional-plasticity of granule cell neurons (GCNs), and expression of plasticityrelated proteins in the dentate gyrus. This review will elaborate on the effects of Meth in animal models during different stages of addiction-like behavior on proliferation, differentiation, maturation, and survival of newly born neural progenitor cells. We will then discuss evidence for the contribution of adult neurogenesis in context-driven Meth-seeking behavior in animal models. These findings from interdisciplinary studies suggest that a subset of newly born GCNs contribute to context-driven Meth-seeking in Meth addicted animals.
\end{abstract}

Keywords: Dentate gyrus, granule cell neurons, drugs of abuse, electrophysiology, addiction, relapse

\section{REVIEW OF ADDICTION}

Addiction is a chronic relapsing disorder associated with profound adaptations in the brain. In the United States, an estimated 23 million people almost one in ten - suffer from addiction to either alcohol or other illicit drugs. These findings indicate that substance use disorders have become a public health issue, and suggest that pharmacological approaches and psychosocial therapies targeting the withdrawal/negative affect stage of addiction could prevent propensity for relapse and reduce the socio and economic costs associated with substance use disorders [1-3].

Addiction is characterized by three factors or stages [4], and is now recognized as a chronic relapsing disease that can change both brain structure and function, ultimately leading to alterations in brain circuitry [5]. Like any other diseases such as diabetes,

\footnotetext{
*Correspondence to: Chitra D. Mandyam, Department of Anesthesiology, University of California San Diego, VA San Diego Healthcare System, San Diego, CA, USA. E-mail: cmandyam@ scripps.edu.
}

cancer, or heart disease, addiction to illicit drugs is caused by a combination of biological, behavioral, and environmental factors. Although genetic vulnerability certainly contributes to the risk of developing addiction, behavior plays a critical role especially when it comes to reinforcing a habit [6]. Notably, elegant functional studies in preclinical models of addiction-like behavior demonstrate that addiction is a complex disorder and can directly affect the reward-, pleasure-, motivation-pathway in the brain, and compromise memory functions which can assist with preserving memories associated with drug context, cues, and the drug itself $[7,8]$.

\section{HIPPOCAMPUS IN ADDICTION}

The hippocampus is essential for acquisition of new memories $[9,10]$. It consists of three subdivisions: dentate gyrus (DG), cornu ammonis (CA) 1 , and CA3. Information is propagated from the entorhinal cortex (EC) to DG, DG to CA3 pyramidal neurons (mossy fibers), from CA3 to CA1 pyramidal neurons (Schaffer collaterals), and CA1 
pyramidal neurons in turn project back to the cortex in unidirectional, feed-forward excitation manner forming the "tri-synaptic hippocampal circuit" [11, $12]$. Excitatory perforant path fibers from the $\mathrm{EC}$ are the major afferents projecting to the DG [13]. Each region involved in the tri-synaptic circuit has specific cell types and functional plasticity contributing to the storage, consolidation, retrieval of declarative, spatial, and associative long-term memory [10, 14-17]. The hippocampus is hypothesized to play a major role in the context of neurobiological alterations that could assist with the process of addiction-like behavior and propensity to relapse [18-20]. For example, the hippocampus stores information about environmental cues associated with the drug [21-26]. These memories help create a conditioned response - craving - whenever the individual encounters those related environmental cues. This is supported by the fact that approximately 40 to $60 \%$ of individuals who are addicted experience at least one relapse episode after an initial recovery. Therefore, behavioral therapies, including extinction learning are now aimed at helping individuals to unlearn the drug cues and context associated with the drug, while adopting healthier coping strategies to reduce or prevent relapse [27-30].

\section{ADULT NEUROGENESIS IN THE HIPPOCAMPUS}

The DG is of particular interest as newly born granule cell neurons (GCNs) are continuously generated throughout adulthood via a process called neurogenesis in the adult mammalian brain [31-33]. Therefore, the functional contribution of newly born and preexisting (mature) GCNs to circuitry in the DG and the DG-dependent memory formation are being explored in several laboratories.

Over the past decade, the maturation process, integration of newly born GCNs into the existing hippocampal network, and the functional significance of neurogenesis has been researched extensively [33-36]. General consensus asserts that it takes approximately one month for progenitor cells born from precursor radial glia-like stem cells to develop into newly born GCNs and additional weeks are required for full maturation of GCNs [34]. During the first month, subgranular zone (SGZ) radial glia-like stem cells (Type 1 cells) and progenitor cells (Type 2, Type 3) have been shown to go through developmental stages with distinct morphological, physiological, and molecular characteristics [37] (Figs. 1-3). Newborn GCNs are considered to originate from Type 1 radial glia-like stem cells in the subgranular layer. These cells extend processes into the molecular layer and express markers such as nestin, glial fibrillary acidic protein (GFAP) and Sox2 [38, 39]. Furthermore, Type 1 cells have astrocytic properties including low input resistance and a resting potential near the $K+$ equilibrium potential [40]. Activation of Type 1 cells is mediated by niche factors such as Notch or bone morphogenic protein [41, 42] and the neurotransmitter GABA [43]. Type 1 cells likely give rise to Type 2 progenitor cells under the influence of additional local niche factors [fibroblast growth factor-2 [44], sonic hedgehog [45], vascular endothelial growth factor [46], and Wnt7a [47]]. During the first week of the maturation process, neuronal lineage-committed Type 2 cells begin to migrate into the inner granule cell layer of the DG. Initially, there are no clear dendritic or axonal processes and electrophysiological findings from whole-cell patchclamp recordings indicate that the cells do not show spontaneous synaptic activity [48]. However, these cells are tonically activated by ambient GABA [49]. Electrophysiological recordings from retro-virally labeled cells three days after infection demonstrates that tonic inward excitatory current is selectively blocked by bicuculline, suggesting non-synaptic activation of $\mathrm{GABA}_{\mathrm{A}}$ receptors on 3-day old progenitors [50]. A subset of the cells retain Type 1 stem cell markers such as nestin and Sox2, whereas the remaining Type 2 cells begin to differentiate along a neuronal lineage becoming NeuroD and Prox1 positive and progressing into Type 3 neuroblasts expressing markers such as PSA-NCAM, calretinin and doublecortin before maturing into GCNs [35, 41, 51]. One month later, these cells have the morphological and physiological characteristics of GCNs, though their full maturation and incorporation into functional circuits appears to be a prolonged process (Fig. 1 demonstrates distinct morphological and electrophysiological properties of newly born and mature GCNs in the adult rat; [38, 39]). Adult-born GCN physiology, plasticity, and circuitry may continually evolve for at least 3 months [52].

Newly born GCNs are part of an elaborate neural circuitry receiving sequential innervation from structures important for learning and memory function. For example, newly born GCNs receive inputs from septal-hippocampal neurons, transient innervation from mature GCNs, as well as direct feedback from CA3 pyramidal neurons [52]. Newly born GCNs 

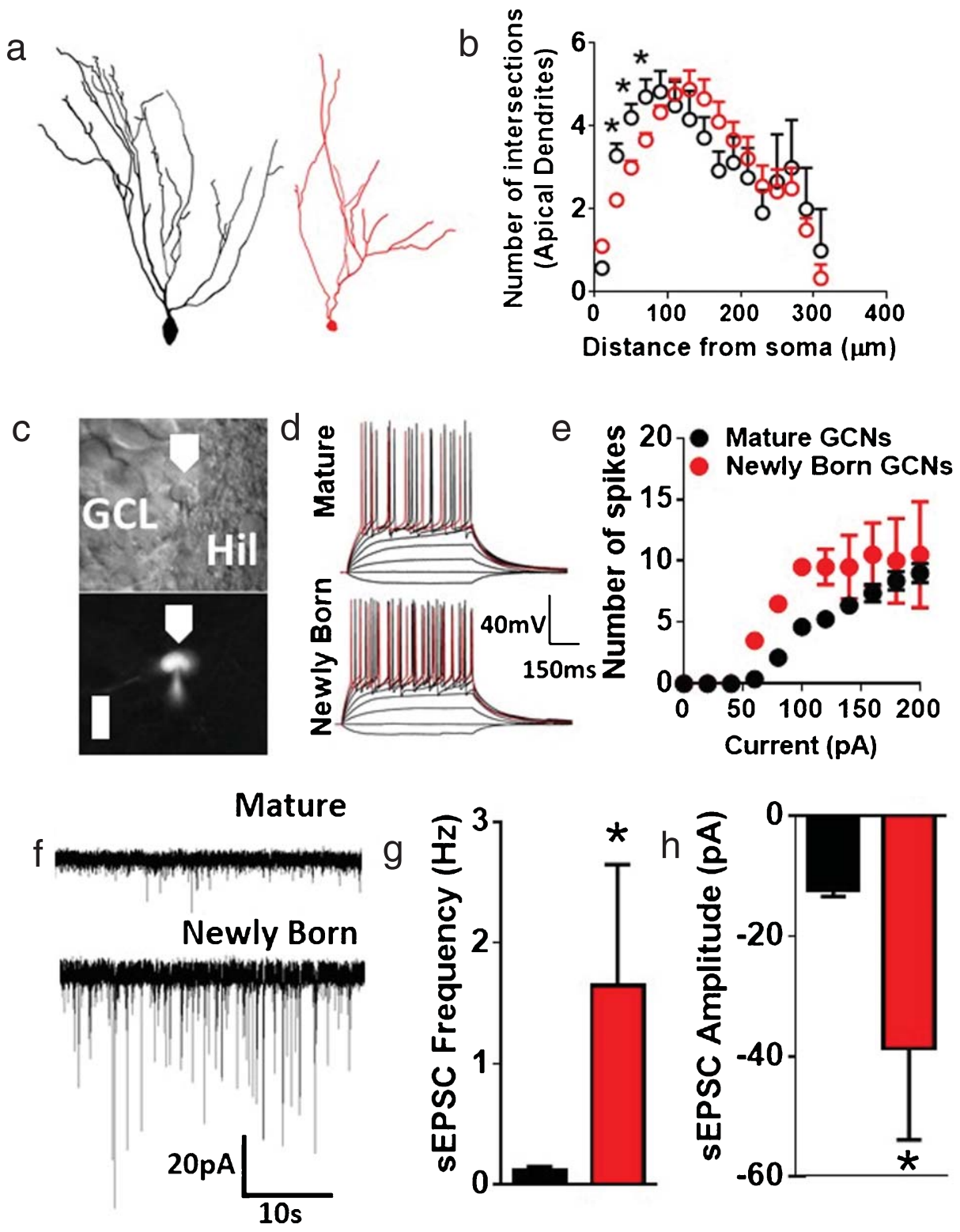

Fig. 1. Distinct morphological and electrophysiological properties of newly born and mature GCNs in the adult PND125 rat. (a, b Modified from [94]. To achieve distinction of newly born GCNs, we injected 12 week old rats with retrovirus (RV) expressing mCherry $(R V-m C)$ into the hilus of the DG (RV was generously provided by Dr. Bryan Luikart, Dartmouth Geisel School of Medicine, $5 \mu 1$ of $5 \times 10^{8}$ infectious units per $\mathrm{ml}$; AP, -3.8 ; ML, \pm 2.7 ; DV, -3.3 ; relative to bregma). RV-mC selectively infects actively dividing cells at the time of injection and the infected cells express mCherry for the rest of their lifespan. This strategy allows us to distinguish newly born GCNs from mature (pre-existing, unlabeled) GCNs, and target for histochemical [94] and electrophysiological [129] analysis. a) 3D Sholl analysis of dendritic arborization of apical dendrites of mature (Golgi-Cox labeled) and newly born (21-day-old RV-mC labeled) GCNs in the DG of adult male rats. $n=24-28$ neurons from $6-8$ rats. ${ }^{*} p<0.05$ vs. newly born GCNs by two-way ANOVA repeated measures. b) Structure of mature (black) and newly born (red) GCNs from Sholl analysis. c) Coronal section through the DG indicating the granule cell layer (GCL) with GCNs used for electrophysiology. Top panel shows image acquired under infrared differential interference contrast optics, and bottom panel shows image acquired under fluorescence optics. White cell is labeled with RV-mC. Recording pipette is also shown in both panels. Scale bar is $15 \mu \mathrm{m}$, applies to both panels. d) Traces representative of action potentials elicited by depolarizing current injections from mature (RV-mC negative) and newly born (RV-mC positive) GCNs. e) $\mathrm{x}-\mathrm{y}$ graph of number of action potential spikes over increasing current injections in mature and newly born GCNs. Newly born GCNs showed a trend towards higher number of spikes compared with mature GCNs ( $p=0.059$ by repeated measures two-way ANOVA). f) Representative traces of sEPSCs in mature and newly born GCNs. g-h) Quantitative data for sEPSC frequency (g) and average amplitude (h) of GCNs. $n=16$ neurons from 4 rats for mature GCNs, $n=4$ neurons from 2 rats for newly born GCNs. ${ }^{*} p<0.05$ vs. mature GCNs by unpaired t test. 

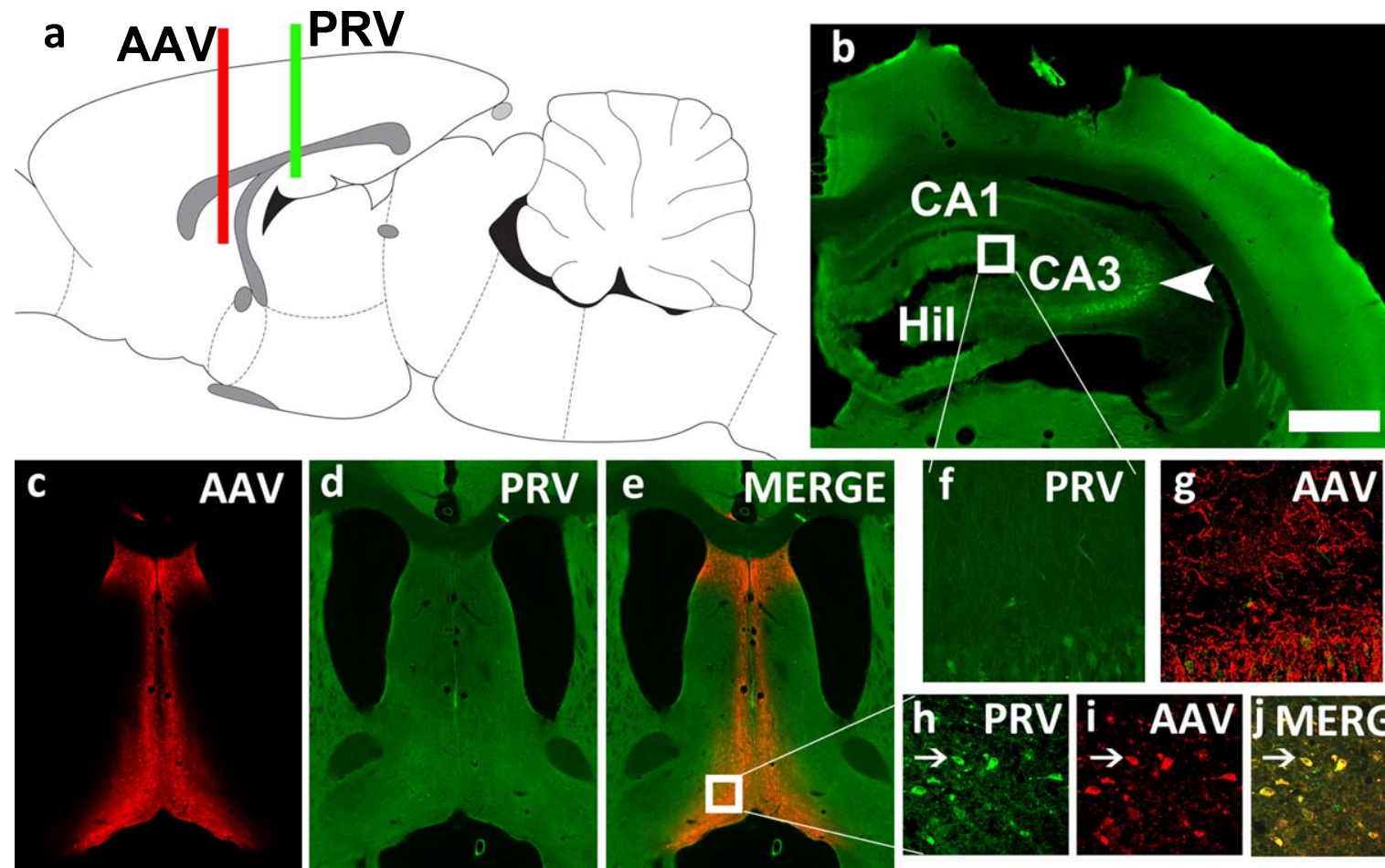

Fig. 2. Septal inputs to the molecular layer and SGZ of the DG in the adult PND125 rat. To identify whether forebrain neurons project axons to the GCNs in adult 12 week old rats, we determined the forebrain afferent inputs from the medial septum into the molecular layer of the DG (a-j). To achieve this, we performed dual virus labeling, using an adeno-associated virus (AAV) that is transported anterogradely down the axon for terminal activation [130,131], and pseudorabies virus bartha-152 (PRV) that is selectively transported retrogradely and labels cell bodies (Card \& Enquist, 2014). We injected synapsin driven AAV1 with the capacity for optogenetic activation (AAV1-Syn-ChrimsonRtdTomato.WPRE.bGH Cat\# AV-1-PV3447; Penn Vector Core; AAV-tdT) into the medial septum $\left(4 \mu 1\right.$ of $2 \times 10^{13}$ infectious units per ml; AP, $+0.2 ; \mathrm{ML}, \pm 0$; DVs, $-6.2,-6.8,-7.2$; relative to bregma; a, c) three weeks prior to PRV injections into the molecular layer of the DG (PRV-152-EGFP was provided by Dr. J. Patrick Card, University of Pittsburgh viral vector core; $1 \mu 1$ of $3 \times 10^{10}$ infectious units per ml; AP, $-4.3 ; \mathrm{ML}, \pm 2.6$; DVs, $-2.8,-3.0,-3.2$; relative to bregma; PRV-GFP; a, c). Rats were euthanized $30 \mathrm{~h}$ after the PRV-GFP injection to maintain labeling of direct inputs to the DG [133]. (a) Sagittal view of the adult rat brain indicating injection sites for AAV-tdT (red) and PRV-GFP (green). (b) Section of the dorsal hippocampus indicating the regions of the hippocampus, CA1, hilus (Hil) and CA3. Arrow head points to PRV-GFP labeled neurons in the CA3 region. (c-e) Confocal images of AAV-tdT and PRV-GFP in the medial septum indicating strong signal of neurons labeled with AAV-tdT (c), PRV-GFP (d) and co-labeling in (e). (f-g) Zoomed in section of the molecular layer of the DG in (b) showing axonal labeling with AAV-tdT. (h-j) Zoomed in section of the medial septum and horizontal nucleus of the diagonal band showing co-labeling of PRV-GFP and AAV-tdT in the neurons. Thin arrow points to co-labeled cell. Scale bar in b is $200 \mu \mathrm{m}$, applies b-e. Scale bar in b is $40 \mu \mathrm{m}$ in $\mathrm{f}-\mathrm{j}$.

receive direct robust input from septal cholinergic neurons, which may be important during the maturation process (Fig. 2 shows septal inputs to the molecular layer and SGZ of the DG in the adult rat). It is possible that newly born GCNs receive septal cholinergic innervation at earlier developmental stages [53], as neurotoxic cholinergic forebrain lesions decrease cell proliferation and neurogenesis in the DG [54, 55], whereas activation of the cholinergic system with donezepil increases new cell survival [56]. After about a month, inputs from perirhinal (PRH) and lateral entorhinal cortex (LEC) become substantial inputs to the newly born GCNs [52], and these are brain areas relevant to the integration of novel sensory and environmental information as well as for processing novel object recognition and familiarity. Additionally, there is stronger input from LEC rather than medial entorhinal cortex (MEC; a region that contains grid cells that are involved in spatial position information) which provides different types of information and may facilitate the role of newly born GCNs in pattern separation. Disruption of new GCN circuitry by PRH/LEC lesions as well as knockdown of adult neurogenesis by focal $\mathrm{x}$-irradiation in the DG led to deficits in fine discrimination in the touchscreen task [52, 57]. Experiments in which neurogenesis is reduced followed by testing in contextual fear conditioning 

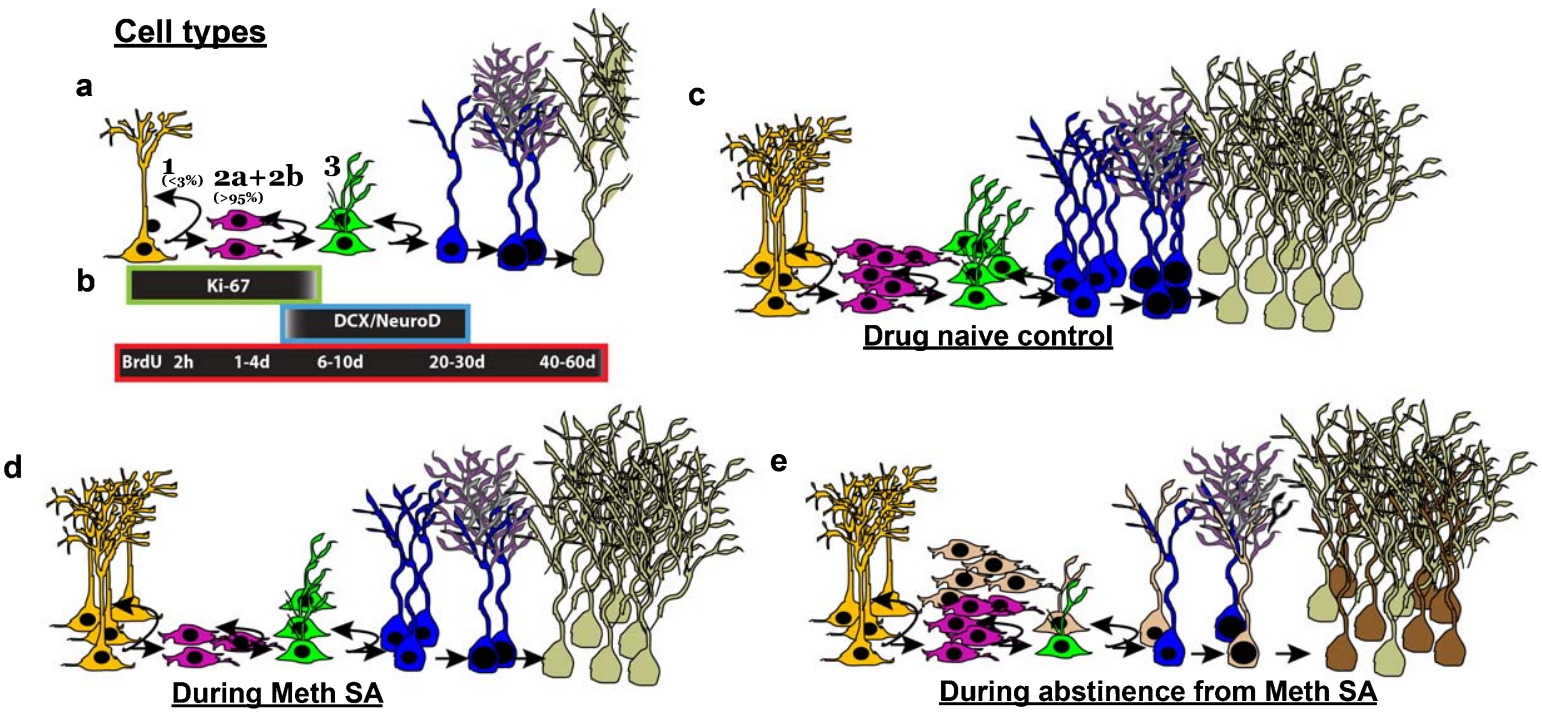

Fig. 3. Methamphetamine (Meth) self-administration (SA) effects the birth and differentiation of neural progenitor cells and neurogenesis in the dentate gyrus of the hippocampus in adult rats. (a) Stages of adult hippocampal neurogenesis. Type 1 putative stem-like cells rarely label with BrdU. BrdU will label rapidly-dividing Type 2 and some Type 3 cells. (b) Endogenous marker Ki-67 labels Types 1, 2, and some Type 3 cells. DCX+ immature neurons can be further divided into younger (Type 3+ve) and older (Type 3-ve). BrdU labeling over a time course will determine whether a cell is dividing ( $2 \mathrm{~h}-4 \mathrm{~d}$ ), differentiating (6-10d) or surviving (20\&60 d) post injection. (c-e) Schematic of HR MethSA-induced inhibition of DG neurogenesis and abstinence from HR MethSA-induced aberrant survival of newly born progenitors. (c) Normal levels of cells in each stage of neurogenesis. (d) HR MethSA-induced reduction in the levels of cell division (pink cells), maturation (green cells) differentiation (blue cells) and survival (pale cells) compared with normal control levels. (e) Abstinence-induced increase in cell division, and aberrant survival of newly born progenitors (brown cells) compared with normal control levels.

paradigms or the radial arm maze provide support for a role of newly born GCNs in fine contextual discrimination [58, 59, 60]. In contrast, enhancement of neurogenesis results in improved pattern separation $[61,62]$. These evidences raise the possibility that newly born GCNs may process contextual rather than spatial path integration information.

\section{METHAMPHETAMINE IS A POTENT PSYCHOSTIMULANT}

Meth is a highly addictive psychostimulant drug, which normally takes either a form of white, odorless, bitter-tasting powder/pill or a crystal which looks like glass fragment or shiny, bluish-white rock. Meth is chemically similar to amphetamine, a drug used to treat attention-deficit hyperactivity disorder and narcolepsy. Negative affect in humans is a consequence of chronic Meth abuse, and symptoms include anxiety, confusion, insomnia, mood disturbances, and violent behavior in addition to a number of psychotic features including paranoia, visual and auditory hallucinations, and delusion [63, 64].
In animal models, Meth directly alters the function of neurons by facilitating abundant release of the neurotransmitters such as dopamine, serotonin, and noradrenaline from presynaptic storage sites at the nerve terminals. Overwhelming accumulation of monoamines in the nerve terminals result in structural and functional alterations in neurons located at many regions of the brain that are involved in reward-, pleasure-, motivation-pathway, and memory which may account for many emotional and cognitive deficits associated with Meth addiction-like behavior [65-68].

Evidence from clinical and preclinical studies have demonstrated that Meth addiction and addictionlike behavior is linked to a decreased volume of limbic-related structures $[69,70]$, altered hippocampal morphology [71, 72], and hippocampal-related deficits in learning and memory [73, 74]. Given the fact that the hippocampus plays an essential role in learning and memory processes [9, 15, 75-78] and increasing number of evidence suggests that adult hippocampal neurogenesis is a critical element in hippocampus-dependent learning and memory [79-81], it is important to evaluate Meth-induced 
maladaptive plasticity in the hippocampus via alteration in adult neurogenesis and how it contributes to the addictive process.

\section{RODENT MODELS OF METHAMPHETAMINE ADDICTION}

An increase in Meth availability, or a history of Meth intake, has been shown to accelerate the development of dependence in humans [82, 83]. In rats, an extended duration of access to Meth (6 hr/day) for a few sessions produces escalation in Meth self-administration (MethSA) [73, 84-86], demonstrating dramatic increases in drug intake over time that mirror maladaptive patterns of Meth intake in humans and therefore addiction-like behavior in animals. It has been demonstrated that excessive drug taking in addicted animals via extended access schedule involves important perturbations in the stress response systems, and contributes to both the positive reinforcement associated with impulsivity (binge stage of the addiction cycle) and the negative reinforcement of the withdrawal/negative affect stage of the addiction cycle and closely mimic the human patterns of self-administration and addiction [2, 87-92]. This pattern of excessive drug taking, therefore, is designed to study addiction-like behavior. MethSA with extended access, therefore, has significant clinical relevance, and provides a useful approach to understanding the neurobiological mechanisms underlying excessive and compulsive intake [93]. Taken together, MethSA with extended access represents a particularly suitable model for testing our hypothesis that alterations in adult neurogenesis in the DG caused by Meth are partially responsible for the addictive behavior. Findings from our laboratory show that rats that experienced extended access MethSA either showed compulsive-like MethSA (high responders, HR) or noncompulsive-like MethSA (low responders, LR) based on escalation criteria [94]. After MethSA sessions, HR and LR were withdrawn from Meth and after a period of protracted abstinence (22 days; a timeframe required for preneuronal progenitor cells to become newly born GCNs), all animals were tested for reinstatement of drug seeking in an A-B-A self-administration (context A)-extinction (context B)-reinstatement (context A) paradigm [95]. Most notable is that, HR rats with higher levels of MethSA also exhibit a higher propensity for contextdriven reinstatement of Meth-seeking after a period of abstinence [94]. These findings support previous studies that have reported higher reinstatement of cocaine seeking in HR cocaine animals [96, 97] and demonstrate that animals with preferentially higher levels of drug intake are powerful models for identifying neurobiological factors involved in the acquisition, maintenance and risk of relapse and provide a means to increase our understanding of addiction-like behaviors using rodent models.

\section{ROLE OF ADULT NEUROGENESIS IN THE DG IN METH SEEKING}

Recent evidence from our laboratory and others demonstrate that adult neurogenesis could be involved in the altered neuroplasticity in the DG that underlies Meth addiction. Experimenter-delivered [98-100] and self-administered Meth [71, 86] in rodents negatively impact proliferation, survival, and neurogenesis of neural stem cells in the DG. Experimenter-delivered and MethSA produces hippocampal cell death $[71,101]$, suggesting a potential role for cell death in Meth-induced reduction of neurogenesis. Recent studies from others and our laboratory have explored the cellular mechanisms underlying Meth-induced inhibition of neurogenesis. Experimenter-delivered Meth decreased 1-day-old and 7-day-old 5-bromo-2'-deoxyuridine cells [BrdU; single injection of BrdU labels synthesis (S) phase neural stem cells, and the age of the cell at the time of euthanasia determines proliferation ( $2 \mathrm{~h}-4 \mathrm{~d})$, differentiation and maturation (6-10 d), and survival and integration (20-60 d) stages [102, 103]], suggesting that Meth inhibited the proliferation and differentiation of neural stem cells $[98,99]$. Our work shows that MethSA in HR rats decreased the number of $2 \mathrm{~h}$-old BrdU cells, Ki-67-labeled dividing cells [Ki67 is expressed in actively dividing neural stem cells and provides an estimate of net proliferation [104]], reduced the levels of doublecortin (DCX)-labeled immature neurons [DCX is expressed in cells committed to a neuronal phenotype [102]] and decreased the number of 28-day old BrdU cells during Meth experience, indicating that MethSA inhibits the proliferation, differentiation, maturation and survival of neural stem cells [71, 74, 86] (Fig. 3). Detailed cell cycle kinetic analysis demonstrates that reduced proliferation in HR MethSA rats was attributed to reduced levels of progenitors in the $S$ phase of the cell cycle without significant modifications in the length of the $\mathrm{S}$ phase of the cell cycle [86]. Additional 
findings indicate that HR MethSA reduces net proliferation of progenitors and immature neurons by reducing the number of actively dividing preneuronal neuroblasts and increasing the number of dividing preneuronal progenitor cells [86], suggesting that a decrease in the number of progenitors and immature neurons, to a large degree, is attributable to the decrease in the ability of neuroblasts to divide and produce stable progenitor cells that survive as immature neurons [71, 86]. However, abstinence from HR MethSA increases net proliferation of progenitors and survival of newly born GCNs, suggesting that cell intrinsic signals that maintain cell proliferation are differentially regulated during abstinence from HR MethSA [74] (Fig. 3).

Additional findings from our laboratory have demonstrated that adult neurogenesis in the DG is strongly influenced by Meth-taking behavior and moreover, plays a critical role in Meth-seeking behavior [94, 105]. HR MethSA followed by protracted abstinence revealed enhanced neurogenesis (increase in BrdU positive neurons), neuronal activation of GCNs indicated by increase in Fos expression, and compulsive-like contextual-driven Meth reinstatement. Notably, systemic administration of the drug Isoxazole-9 [Isx-9; a synthetic small molecule known to alter neurogenesis in the adult rodent brain [106]] during protracted abstinence blocked enhancement of hippocampal adult neurogenesis, neuronal activation, and compulsive-like contextualdriven Meth reinstatement in HR MethSA rats. In addition, Isx-9 treatment inhibited the modulation of morphological plasticity by Meth, such as reduced arborization, reduced dendritic extent in distal dendrites, and reduced spine density observed in both mature (Golgi-Cox labeled) and newly born GCNs (identified by retro-viral labeling). Lastly, the expression of synaptic proteins associated with learning and memory in DG were altered by Isx-9 (density of total GluN2B was reduced and phosphorylated GluN2B (at Tyr1472) and phosphorylated CaMKII (at Thr286) was enhanced) indicating enhanced activity of plasticity-related proteins [94]. These findings suggest that a subset of newly born GCNs in the DG could directly contribute to Meth-seeking behavior by altering the plasticity in the DG [94].

In the context of the above hypothesis, our laboratory used a pharmacogenetic model to examine the direct role of adult neurogenesis during protracted abstinence from HR MethSA in compulsivelike contextual-driven Meth reinstatement. A GFAPTK rat [107] was used to conditionally ablate neurogenesis in the DG [105]. Male GFAP-TK rats were trained to self-administer Meth on an extended access schedule of reinforcement followed by protracted abstinence, extinction, and reinstatement. During acute withdrawal, GFAP-TK rats were administered with the antiviral drug valganciclovir (Valcyte) to induce apoptosis in actively dividing GFAP type 1 radial glia-like stem cells. Valcyte treatment was continued during abstinence to inhibit adult neurogenesis (indicated by significant decrease in number of cells expressing NeuroD and DCX). Valcyte treatment prevented compulsive-like contextual-driven Meth seeking, and these behavioral effects correlated with reduced or abolished neurogenesis in the DG and reduced activation of CaMKII in the DG. These findings indicate a direct role of newly born GCNs in the DG in context-driven Meth-seeking behavior [105].

HR MethSA also alters the functional plasticity of mature GCNs [108]. The electrophysiological findings from mature GCNs from HR MethSA rats indicate that these neurons have dysregulated neuronal functioning in the basal state and altered functional plasticity that correlated with contextdriven Meth seeking. For example, mature GCNs from reinstated rats have an increased level of spontaneous glutamatergic activity as compared to controls with enhanced frequency and amplitude of sEPSCs, indicating that HR MethSA alters the functional plasticity of mature GCNs [108]. EPSCs of mature GCNs are modulated by newly born GCNs [109]. Therefore, it is possible that aberrant neurogenesis in HR MethSA rats during protracted abstinence could be modulating the basal synaptic properties of mature GCNs. In addition to altered spontaneous glutamatergic activity in mature GCNs, context-driven reinstatement in HR MethSA rats also correlated with altered active and passive membrane properties of mature GCNs, where mature GCNs had reduced number of action potential generation with increased depolarizing current injections compared to controls. It is possible that newly born GCNs during abstinence could affect synaptic transmission in the DG and contribute to the altered intrinsic properties of mature GCNs. Therefore, we demonstrate that new born and mature GCNs differ in intrinsic and synaptic properties in adult rats (Fig. 1), receive synaptic inputs from regions involved in learning and memory (Fig. 2) and support previous findings in young adult rats $[110,111]$ and mice $[49,112-114]$. In the context of forebrain inputs to the hippocampus, cholinergic neurons from the medial septum 
have been demonstrated to be involved in the processes that underlie cocaine reward and addiction [115-117]. Given that psychostimulants cocaine and Meth produce similar neurobiological alterations in the reward and relapse circuitry, future studies are required to determine whether HR MethSA distinctly alters basal synaptic properties, intrinsic properties of new born GCNs and the forebrain-hippocampal circuitry underlying these effects.

\section{SUMMARY AND FUTURE DIRECTIONS}

Evidence accumulated over the past four decades shows that neural stem cells populate in the subgranular zone of the hippocampal DG, where they give rise to GCNs throughout adulthood. Adult neurogenesis in the DG is found in all mammalian species examined, including humans $[118,119]$, and play an essential role in learning and memory. In addition, hippocampal adult neurogenesis may also serve to replace GCNs damaged by brain disorders, including addiction to illicit drugs. Whether they do replace dying or diseased cells, and if so to what extent, and their functional significance are questions currently receiving intense research focus in several brain disorders [33]. During maturation, newly born GCNs exhibit, low input specificity, elevated intrinsic excitablility, reduced GABA-mediated inhibition, and enhanced capacity to undergo activity-dependent synaptic plasticity $[110,112,120]$. The increase in excitability of newly born GCNs suggests functional contribution of neurogenesis to the DG-dependent memory function [121]. Furthermore, these newly born GCNs can modify excitatory synaptic transmission to pre-existing mature GCNs, specifically the excitatory perforant path fiber inputs from the EC to the mature GCNs. For example, enhanced number of newly generated GCNs is associated with reduced excitatory synaptic transmission to mature GCNs mediated by fewer functional synapses, whereas ablation of newly born GCNs is accompanied by increased excitatory synaptic transmission to mature GCNs with no change in intrinsic properties and inhibition [109]. Computational and behavioral models combined with electrophysiological findings indicate that the DG participates in an array of behaviors to assist with hippocampal dependent spatial memory [62]. For example, mature GCNs in the DG communicate with CA3 neurons, mossy cells and hilar interneurons to modulate interference between similar spatial inputs via cognitive discrimination.
Furthermore, newly born GCNs modulate sparseness of activity of mature GCNs through recruitment of feedback inhibition, and via adaptive changes to DG network excitability affect and strengthen cognitive discrimination [122, 123]. Adult neurogenesis may also enable animals to distinguish related stimuli and events rapidly, and support contextual discrimination. In addition to their role in discrimination, new evidence supports the functional significance of neurogenesis in hippocampal memory clearance [124, 125], suggesting that endogenous alterations in neurogenesis and DG excitability could contribute to memory-related disorders [126].

Recent studies are beginning to understand the neural circuits that regulate the function of newly born GCNs. Anatomical and physiological evidence demonstrates that forebrain septal inputs directly activate the mature GCNs and connect to newly born GCNs, increasing the level of afferent excitatory input and thereby granule cell discharge [52, 127, 128]. However, the functional significance of neural circuits that regulate activity of newborn GCNs in modulating DG dependent behaviors is unclear and is under investigation. Future studies should focus on circuitry-level analysis of newly born GCNs, and their role in regulating complex behavior patterns, including drug-seeking behaviors. Such studies could assist with understanding the neurobiology of addiction and open novel therapeutic strategies to treat relapse stage of addiction.

\section{ACKNOWLEDGMENTS}

Preparation of this review was supported by funds from the National Institute on Alcoholism and Alcohol Abuse, National Institute on Drug Abuse (NIDA; AA020098, AA06420 and DA034140 to CDM), start-up funds from VMRF (to CDM) and Department of Veterans Affairs (1I01BX003304 to CDM). The authors would like to thank Ms. McKenzie Fannon for her technical expertise in generating Fig. 2 of the and for her editorial assistance.

\section{REFERENCES}

[1] Koob GF, Volkow ND. Neurocircuitry of addiction. Neuropsychopharmacology. 2010;35:217-38.

[2] Koob GF. The dark side of emotion: The addiction perspective. Eur J Pharmacol. 2015;753:73-87.

[3] Koob GF, Volkow ND. Neurobiology of addiction: A neurocircuitry analysis. The lancet. Psychiatry. 2016;3: 760-73. 
[4] Koob GF, Sanna PP, Bloom FE. Neuroscience of addiction. Neuron. 1998b;21:467-76.

[5] Koob GF, Rocio M, Carrera A, Gold LH, Heyser CJ, Maldonado-Irizarry C, Markou A, Parsons LH, Roberts AJ, Schulteis G, Stinus L, Walker JR, Weissenborn R, Weiss F. Substance dependence as a compulsive behavior. J Psychopharmacol. 1998a;12:39-48.

[6] Egervari G, Ciccocioppo R, Jentsch JD, Hurd YL. Shaping vulnerability to addiction - the contribution of behavior, neural circuits and molecular mechanisms. Neurosci Biobehav Rev. 2017.

[7] Kalivas PW, Volkow ND. The neural basis of addiction: A pathology of motivation and choice. Am J Psychiatry. 2005;162:1403-13.

[8] Kalivas PW, Volkow ND. New medications for drug addiction hiding in glutamatergic neuroplasticity. Mol Psychiatry. 2011;16:974-86.

[9] Scoville WB, Milner, B. Loss of recent memory after bilateral hippocampal lesions. Journal of Neurology, Neurosurgery, and Psychiatry. 1957;20:11-21.

[10] Squire LR, Stark CE, Clark RE. The medial temporal lobe. Annu Rev Neurosci. 2004;27:279-306.

[11] Swanson LW, Wyss JM, Cowan WM. An autoradiographic study of the organization of intrahippocampal association pathways in the rat. J Comp Neurol. 1978;181:681-715.

[12] Amaral DG, Witter MP. The three-dimensional organization of the hippocampal formation: A review of anatomical data. Neuroscience. 1989;31:571-91.

[13] Andersen P, Holmqvist B, Voorhoeve PE. Excitatory synapses on hippocampal apical dendrites activated by entorhinal stimulation. Acta Physiol Scand. 1966;66: 461-72.

[14] Nakazawa T, Komai S, Tezuka T, Hisatsune C, Umemori H, Semba K, Mishina M, Manabe T, Yamamoto T. Characterization of Fyn-mediated tyrosine phosphorylation sites on GluR epsilon 2 (NR2B) subunit of the N-methyl-Daspartate receptor. J Biol Chem. 2001;276:693-9.

[15] Burgess N, Maguire EA, O'Keefe J. The human hippocampus and spatial and episodic memory. Neuron. 2002;35:625-41

[16] Gold AE, Kesner RP. The role of the CA3 subregion of the dorsal hippocampus in spatial pattern completion in the rat. Hippocampus. 2005;15:808-14.

[17] Nakazawa T, Komai S, Watabe AM, Kiyama Y, Fukaya M, Arima-Yoshida F, Horai R, Sudo K, Ebine K, Delawary M, Goto J, Umemori H, Tezuka T, Iwakura Y, Watanabe M, Yamamoto T, Manabe T. NR2B tyrosine phosphorylation modulates fear learning as well as amygdaloid synaptic plasticity. Embo J. 2006;25:2867-77.

[18] Belujon P, Grace AA. Hippocampus, amygdala, and stress: Interacting systems that affect susceptibility to addiction. Ann N Y Acad Sci. 2011;1216:114-21.

[19] Canales JJ. Deficient plasticity in the hippocampus and the spiral of addiction: Focus on adult neurogenesis. Current Topics in Behavioral Neurosciences. 2013;15:293-312.

[20] Castilla-Ortega E, Serrano A, Blanco E, Araos P, Suarez J, Pavon FJ, Rodriguez de Fonseca F, Santin LJ. A place for the hippocampus in the cocaine addiction circuit: Potential roles for adult hippocampal neurogenesis. Neurosci Biobehav Rev. 2016;66:15-32.

[21] Knierim JJ, Lee I, Hargreaves EL. Hippocampal place cells: Parallel input streams, subregional processing, and implications for episodic memory. Hippocampus. 2006; 16:755-64.
[22] Lisman JE. Role of the dual entorhinal inputs to hippocampus: A hypothesis based on cue/action (non-self/self) couplets. Prog Brain Res. 2007;163:615-25.

[23] Tipps ME, Raybuck JD, Lattal KM. Substance abuse, memory, and post-traumatic stress disorder. Neurobiol Learn Mem. 2014;112:87-100.

[24] Goodman J, Packard MG. Memory Systems and the Addicted Brain. Frontiers in Psychiatry. 2016;7:24.

[25] Kang E, Wen Z, Song H, Christian KM, Ming GL. Adult neurogenesis and psychiatric disorders. Cold Spring Harbor Perspectives in Biology. 2016;8.

[26] Kutlu MG, Gould TJ. Effects of drugs of abuse on hippocampal plasticity and hippocampus-dependent learning and memory: Contributions to development and maintenance of addiction. Learn Mem. 2016;23:515-33.

[27] Benowitz NL, Nardone N, Dains KM, Hall SM, Stewart S, Dempsey D, Jacob 3rd P. Effect of reducing the nicotine content of cigarettes on cigarette smoking behavior and tobacco smoke toxicant exposure: 2-year follow up. Addiction. 2015;110:1667-75.

[28] Sheynin J, Moustafa AA, Beck KD, Servatius RJ, Casbolt PA, Haber P, Elsayed M, Hogarth L, Myers CE. Exaggerated acquisition and resistance to extinction of avoidance behavior in treated heroin-dependent men. J Clin Psychiatry. 2016;77:386-94.

[29] Thome J, Koppe G, Hauschild S, Liebke L, Schmahl C, Lis, S, Bohus M. Modification of Fear Memory by Pharmacological and Behavioural Interventions during Reconsolidation. PLoS One. 2016;11:e0161044.

[30] Xue YX, Deng JH, Chen YY, Zhang LB, Wu P, Huang GD, Luo YX, Bao YP, Wang YM, Shaham Y, Shi J, Lu, L. Effect of Selective Inhibition of Reactivated Nicotine-Associated Memories With Propranolol on Nicotine Craving. JAMA Psychiatry. 2017;74:224-32.

[31] Altman J, Das GD. Autoradiographic and histological evidence of postnatal hippocampal neurogenesis in rats. J Comp Neurol. 1965;124:319-35.

[32] Cameron HA, McKay R. Stem cells and neurogenesis in the adult brain. Current Opinion in Neurobiology. 1998;8:677-80.

[33] Ming GL, Song H. Adult neurogenesis in the mammalian brain: Significant answers and significant questions. Neuron. 2011;70:687-702.

[34] Zhao C, Deng W, Gage FH. Mechanisms and functional implications of adult neurogenesis. Cell. 2008;132:64560.

[35] Suh H, Deng W, Gage FH. Signaling in adult neurogenesis. Annu Rev Cell Dev Biol. 2009;25:253-75.

[36] Deng W, Aimone JB, Gage FH. New neurons and new memories: How does adult hippocampal neurogenesis affect learning and memory? Nat Rev Neurosci. 2010;11: 339-50.

[37] Abrous DN, Koehl M, Le Moal M. Adult neurogenesis: From precursors to network and physiology. Physiol Rev. 2005;85:523-69.

[38] Enikolopov G, Overstreet-Wadiche L, Ge, S. Viral and transgenic reporters and genetic analysis of adult neurogenesis. Cold Spring Harbor Perspectives in Biology. 2015;7:a018804.

[39] Goncalves JT, Schafer ST, Gage FH. Adult Neurogenesis in the Hippocampus: From Stem Cells to Behavior. Cell. 2016;167:897-914.

[40] Filippov V, Kronenberg G, Pivneva T, Reuter K, Steiner B, Wang LP, Yamaguchi M, Kettenmann H, Kempermann 
G. Subpopulation of nestin-expressing progenitor cells in the adult murine hippocampus shows electrophysiological and morphological characteristics of astrocytes. Mol Cell Neurosci. 2003;23:373-82.

[41] Lugert S, Basak O, Knuckles P, Haussler U, Fabel K, Gotz M, Haas CA, Kempermann G, Taylor V, Giachino C. Quiescent and active hippocampal neural stem cells with distinct morphologies respond selectively to physiological and pathological stimuli and aging. Cell Stem Cell. 2010;6:445-56.

[42] Mira H, Andreu Z, Suh H, Lie DC, Jessberger S, Consiglio A, San Emeterio J, Hortiguela R, Marques-Torrejon MA, Nakashima K, Colak D, Gotz M, Farinas I, Gage FH. Signaling through BMPR-IA regulates quiescence and long-term activity of neural stem cells in the adult hippocampus. Cell Stem Cell. 2010;7:78-89.

[43] Song J, Zhong C, Bonaguidi MA, Sun GJ, Hsu D, Gu Y, Meletis K, Huang ZJ, Ge S, Enikolopov G, Deisseroth K, Luscher B, Christian KM, Ming GL, Song $H$. Neuronal circuitry mechanism regulating adult quiescent neural stem-cell fate decision. Nature. 2012;489: 150-4.

[44] Jin K, Sun Y, Xie L, Batteur S, Mao XO, Smelick C, Logvinova A, Greenberg DA. Neurogenesis and aging: FGF-2 and HB-EGF restore neurogenesis in hippocampus and subventricular zone of aged mice. Aging Cell. 2003;2:175-83.

[45] Lai K, Kaspar BK, Gage FH, Schaffer DV. Sonic hedgehog regulates adult neural progenitor proliferation in vitro and in vivo. Nat Neurosci. 2003;6:21-7.

[46] Cao L, Jiao X, Zuzga DS, Liu Y, Fong DM, Young D, During MJ. VEGF links hippocampal activity with neurogenesis, learning and memory. Nat Genet. 2004;36: 827-35.

[47] Qu Q, Sun G, Li W, Yang S, Ye P, Zhao C, Yu RT, Gage FH, Evans RM, Shi Y. Orphan nuclear receptor TLX activates $\mathrm{Wnt} /$ beta-catenin signalling to stimulate neural stem cell proliferation and self-renewal. Nat Cell Biol. 2010;12, 3140; sup:31-9.

[48] Esposito MS, Piatti VC, Laplagne DA, Morgenstern NA, Ferrari CC, Pitossi FJ, Schinder AF. Neuronal differentiation in the adult hippocampus recapitulates embryonic development. J Neurosci. 2005;25:10074-86.

[49] Dieni CV, Panichi R, Aimone JB, Kuo CT, Wadiche JI, Overstreet-Wadiche L. Low excitatory innervation balances high intrinsic excitability of immature dentate neurons. Nat Commun. 2016;7:11313.

[50] Ge S, Goh EL, Sailor KA, Kitabatake Y, Ming GL, Song H. GABA regulates synaptic integration of newly generated neurons in the adult brain. Nature. 2006;439:589-93.

[51] Encinas JM, Vaahtokari A, Enikolopov G. Fluoxetine targets early progenitor cells in the adult brain. Proc Natl Acad Sci USA. 2006;103:8233-8.

[52] Vivar C, Potter MC, Choi J, Lee JY, Stringer TP, Callaway EM, Gage FH, Suh, H, van Praag H. Monosynaptic inputs to new neurons in the dentate gyrus. Nat Commun. 2012;3:1107.

[53] Ide Y, Fujiyama F, Okamoto-Furuta K, Tamamaki N, Kaneko T, Hisatsune T. Rapid integration of young newborn dentate gyrus granule cells in the adult hippocampal circuitry. Eur J Neurosci. 2008;28:2381-92.

[54] Cooper-Kuhn CM, Winkler J, Kuhn HG. Decreased neurogenesis after cholinergic forebrain lesion in the adult rat. J Neurosci Res. 2004;77:155-65.
[55] Mohapel P, Leanza G, Kokaia, M, Lindvall O. Forebrain acetylcholine regulates adult hippocampal neurogenesis and learning. Neurobiol Aging. 2005;26:939-46.

[56] Kaneko N, Okano H, Sawamoto, K. Role of the cholinergic system in regulating survival of newborn neurons in the adult mouse dentate gyrus and olfactory bulb. Genes Cells. 2006;11:1145-59.

[57] Clelland CD, Choi M, Romberg C, Clemenson Jr GD, Fragniere A, Tyers P, Jessberger S, Saksida LM, Barker RA, Gage FH, Bussey TJ. A functional role for adult hippocampal neurogenesis in spatial pattern separation. Science. 2009;325:210-3.

[58] Guo W, Allan AM, Zong R, Zhang L, Johnson EB, Schaller EG, Murthy AC, Goggin SL, Eisch AJ, Oostra BA, Nelson DL, Jin, P, Zhao X. Ablation of Fmrp in adult neural stem cells disrupts hippocampus-dependent learning. Nat Med. 2011;17:559-65.

[59] Nakashiba T, Cushman JD, Pelkey KA, Renaudineau S, Buhl DL, McHugh TJ, Rodriguez Barrera V, Chittajallu R, Iwamoto KS, McBain CJ, Fanselow MS, Tonegawa S. Young dentate granule cells mediate pattern separation, whereas old granule cells facilitate pattern completion. Cell. 2012;149:188-201.

[60] Tronel S, Belnoue L, Grosjean N, Revest JM, Piazza PV, Koehl M, Abrous DN. Adult-born neurons are necessary for extended contextual discrimination. Hippocampus. 2012;22:292-8.

[61] Creer DJ, Romberg C, Saksida LM, van Praag H, Bussey TJ. Running enhances spatial pattern separation in mice. Proc Natl Acad Sci U S A. 2010;107:2367-72.

[62] Sahay A, Scobie KN, Hill AS, O'Carroll CM, Kheirbek MA, Burghardt NS, Fenton AA, Dranovsky, A, Hen R. Increasing adult hippocampal neurogenesis is sufficient to improve pattern separation. Nature. 2011;472:466-70.

[63] NIDA. Research reports: Methamphetamine abuse and addiction. The Science of Drug Abuse and Addiction, 2006.

[64] NIDA. Drug Facts: Methamphetamine. The Science of Drug Abuse and Addiction, 2010.

[65] Cadet JL, Jayanthi S, Deng X. Speed kills: Cellular and molecular bases of methamphetamine-induced nerve terminal degeneration and neuronal apoptosis. Faseb J. 2003; 17:1775-88.

[66] Gettig JP, Grady SE, Nowosadzka I. Methamphetamine: Putting the brakes on speed. J Sch Nurs. 2006;22:66-73.

[67] Carvalho M, Carmo H, Costa VM, Capela JP, Pontes H, Remiao F, Carvalho, F, Bastos Mde L. Toxicity of amphetamines: An update. Archives of toxicology. 2012; 86:1167-231.

[68] Ares-Santos S, Granado N, Moratalla R. The role of dopamine receptors in the neurotoxicity of methamphetamine. J Intern Med. 2013;273:437-53.

[69] Schwartz DL, Mitchell AD, Lahna DL, Luber HS, Huckans MS, Mitchell SH, Hoffman WF. Global and local morphometric differences in recently abstinent methamphetamine-dependent individuals. Neuroimage. 2010;50:1392-401.

[70] Simon SL, Dean AC, Cordova X, Monterosso JR, London ED. Methamphetamine dependence and neuropsychological functioning: Evaluating change during early abstinence. J Stud Alcohol Drugs. 2010;71:335-44.

[71] Mandyam CD, Wee S, Crawford EF, Eisch AJ, Richardson HN, Koob GF. Varied access to intravenous methamphetamine self-administration differentially alters adult 
hippocampal neurogenesis. Biol Psychiatry. 2008;64: 958-65.

[72] Kim YT, Lee JJ, Song HJ, Kim JH, Kwon DH, Kim MN, Yoo DS, Lee HJ, Kim HJ, Chang Y. Alterations in cortical activity of male methamphetamine abusers performing an empathy task: fMRI study. Hum Psychopharmacol. 2010;25:63-70.

[73] Rogers JL, De Santis S, See RE. Extended methamphetamine self-administration enhances reinstatement of drug seeking and impairs novel object recognition in rats. Psychopharmacology (Berl). 2008;199:615-24.

[74] Recinto P, Samant AR, Chavez G, Kim A, Yuan CJ, Soleiman M, Grant Y, Edwards S, Wee S, Koob GF, George O, Mandyam CD. Levels of neural progenitors in the hippocampus predict memory impairment and relapse to drug seeking as a function of excessive methamphetamine self-administration. Neuropsychopharmacology. 2012;37:1275-87.

[75] Black AH, Nadel, L, O'Keefe J. Hippocampal function in avoidance learning and punishment. Psychol Bull. 1977;84:1107-29.

[76] Morris RG, Garrud P, Rawlins JN, O'Keefe J. Place navigation impaired in rats with hippocampal lesions. Nature. 1982;297:681-3.

[77] Eichenbaum H, Otto, T, Cohen NJ. The hippocampuswhat does it do? Behav Neural Biol. 1992;57:2-36.

[78] Riedel G, Micheau J, Lam AG, Roloff EL, Martin SJ, Bridge H, de Hoz L, Poeschel B, McCulloch J, Morris RG. Reversible neural inactivation reveals hippocampal participation in several memory processes. Nat Neurosci. 1999;2:898-905.

[79] van Praag H, Christie BR, Sejnowski TJ, Gage FH. Running enhances neurogenesis, learning, and longterm potentiation in mice. Proc Natl Acad Sci U S A. 1999;96:13427-31.

[80] Shors TJ, Miesegaes G, Beylin A, Zhao M, Rydel T, Gould E. Neurogenesis in the adult is involved in the formation of trace memories. Nature. 2001;410:372-6.

[81] Jessberger S, Clark RE, Broadbent NJ, Clemenson Jr GD, Consiglio A, Lie DC, Squire LR, Gage FH. Dentate gyrusspecific knockdown of adult neurogenesis impairs spatial and object recognition memory in adult rats. Learn Mem. 2009;16:147-54.

[82] Kramer JC, Fischman VS, Littlefield DC. Amphetamine abuse. Pattern and effects of high doses taken intravenously. Jama. 1967;201:305-9.

[83] Gawin FH, Ellinwood Jr EH. Cocaine dependence. Annu Rev Med. 1989;40:149-61.

[84] Kitamura O, Wee S, Specio SE, Koob GF, Pulvirenti L. Escalation of methamphetamine self-administration in rats: A dose-effect function. Psychopharmacology (Berl). 2006;186:48-53.

[85] Mandyam CD, Wee S, Eisch AJ, Richardson HN, Koob GF. Methamphetamine self-administration and voluntary exercise have opposing effects on medial prefrontal cortex gliogenesis. J Neurosci. 2007;27:11442-50.

[86] Yuan CJ, Quiocho JM, Kim A, Wee S, Mandyam CD. Extended access methamphetamine decreases immature neurons in the hippocampus which results from loss and altered development of neural progenitors without altered dynamics of the S-phase of the cell cycle. Pharmacol Biochem Behav. 2011;100:98-108.

[87] Koob GF. Drug addiction: The yin and yang of hedonic homeostasis. Neuron. 1996;16:893-6.
[88] Koob GF. Stress, corticotropin-releasing factor, and drug addiction. Ann N Y Acad Sci. 1999;897:27-45.

[89] Koob GF. Neurobiology of addiction. Toward the development of new therapies. Ann N Y Acad Sci. 2000;909: 170-85.

[90] Koob GF. A role for brain stress systems in addiction. Neuron. 2008;59:11-34.

[91] Koob GF. New dimensions in human laboratory models of addiction. Addict Biol. 2009b;14:1-8.

[92] Koob GF. Neurobiological substrates for the dark side of compulsivity in addiction. Neuropharmacology. 2009a;56(Suppl 1):18-31.

[93] Ahmed SH, Koob GF. Transition from moderate to excessive drug intake: Change in hedonic set point. Science. 1998;282:298-300.

[94] Galinato MH, Lockner JW, Fannon-Pavlich MJ, Sobieraj JC, Staples MC, Somkuwar SS, Ghofranian A, Chaing S, Navarro AI, Joea A, Luikart BW, Janda KD, Heyser C, Koob GF, Mandyam CD. A synthetic small-molecule Isoxazole-9 protects against methamphetamine relapse. Mol Psychiatry. 2018 Mar;23(3):629-638.

[95] Shaham Y, Shalev U, Lu L, De Wit H, Stewart J. The reinstatement model of drug relapse: History, methodology and major findings. Psychopharmacology (Berl). 2003;168:3-20.

[96] Piazza PV, Deroche-Gamonent V, Rouge-Pont F, Le Moal, M. Vertical shifts in self-administration dose-response functions predict a drug-vulnerable phenotype predisposed to addiction. J Neurosci. 2000;20:4226-32.

[97] Sutton MA, Karanian DA, Self DW. Factors that determine a propensity for cocaine-seeking behavior during abstinence in rats. Neuropsychopharmacology. 2000;22:626-41.

[98] Hildebrandt K, Teuchert-Noodt G, Dawirs RR. A single neonatal dose of methamphetamine suppresses dentate granule cell proliferation in adult gerbils which is restored to control values by acute doses of haloperidol. J Neural Transm. 1999; 106:549-58.

[99] Teuchert-Noodt G, Dawirs RR, Hildebrandt, K. Adult treatment with methamphetamine transiently decreases dentate granule cell proliferation in the gerbil hippocampus. J Neural Transm. 2000;107:133-43.

[100] Kochman LJ, Fornal CA, Jacobs BL. Suppression of hippocampal cell proliferation by short-term stimulant drug administration in adult rats. Eur J Neurosci. 2009;29: 2157-65.

[101] Schmued LC, Bowyer JF. Methamphetamine exposure can produce neuronal degeneration in mouse hippocampal remnants. Brain Res. 1997;759:135-40.

[102] Brown JP, Couillard-Despres S, Cooper-Kuhn CM, Winkler J, Aigner L, Kuhn HG. Transient expression of doublecortin during adult neurogenesis. J Comp Neurol. 2003;467:1-10.

[103] Dayer AG, Ford AA, Cleaver KM, Yassaee M, Cameron HA. Short-term and long-term survival of new neurons in the rat dentate gyrus. J Comp Neurol. 2003;460:563-72.

[104] Gerdes J, Lemke H, Baisch H, Wacker HH, Schwab $\mathrm{U}$, Stein, H. Cell cycle analysis of a cell proliferationassociated human nuclear antigen defined by the monoclonal antibody Ki-67. Journal of Immunology. 1984;133: 1710-5.

[105] Galinato MH, Takashima Y, Fannon MJ, Quach LW, Morales Silva RJ, Mysore KK, Terranova MJ, Dutta RR, Ostrom RW, Somkuwar SS, Mandyam CD. 
Neurogenesis during abstinence is necessary for contextdriven methamphetamine-related memory. J Neurosci. 2018;38:2029-42.

[106] Petrik D, Jiang Y, Birnbaum SG, Powell CM, Kim MS, Hsieh J, Eisch AJ. Functional and mechanistic exploration of an adult neurogenesis-promoting small molecule. FASEB J. 2012.

[107] Snyder JS, Grigereit L, Russo A, Seib DR, Brewer M, Pickel, J, Cameron HA. A Transgenic Rat for Specifically Inhibiting Adult Neurogenesis. ENeuro. 2016;3.

[108] Takashima Y, Fannon MJ, Galinato MH, Steiner NL, An M, Zemljic-Harpf AE, Somkuwar SS, Head BP, Mandyam CD. Neuroadaptations in the dentate gyrus following contextual cued reinstatement of methamphetamine seeking. Brain Struct Funct. 2018.

[109] Adlaf EW, Vaden RJ, Niver AJ, Manuel AF, Onyilo VC, Araujo MT, Dieni CV, Vo HT, King GD, Wadiche JI, Overstreet-Wadiche L. Adult-born neurons modify excitatory synaptic transmission to existing neurons. ELife. 2017;6.

[110] Schmidt-Hieber C, Jonas P, Bischofberger J. Enhanced synaptic plasticity in newly generated granule cells of the adult hippocampus. Nature. 2004;429:184-7.

[111] Brunner J, Neubrandt M, Van-Weert S, Andrasi T, Kleine Borgmann FB, Jessberger S, Szabadics J. Adult-born granule cells mature through two functionally distinct states. ELife. 2014;3:e03104.

[112] Ge S, Yang CH, Hsu KS, Ming GL, Song H. A critical period for enhanced synaptic plasticity in newly generated neurons of the adult brain. Neuron. 2007;54:559-66.

[113] Marin-Burgin A, Mongiat LA, Pardi MB, Schinder AF. Unique processing during a period of high excitation/inhibition balance in adult-born neurons. Science. 2012;335:1238-42.

[114] Dieni CV, Nietz AK, Panichi R, Wadiche JI, OverstreetWadiche L. Distinct determinants of sparse activation during granule cell maturation. J Neurosci. 2013;33: 19131-42.

[115] Gong W, Neill DB, Justice Jr JB. Increased sensitivity to cocaine place-preference conditioning by septal lesions in rats. Brain Res. 1995;683:221-7.

[116] Franklin TR, Druhan JP. Expression of Fos-related antigens in the nucleus accumbens and associated regions following exposure to a cocaine-paired environment. Eur J Neurosci. 2000;12:2097-106.

[117] Smith JE, Vaughn TC, Co C. Acetylcholine turnover rates in rat brain regions during cocaine self-administration. $\mathrm{J}$ Neurochem. 2004;88:502-12.

[118] Eriksson PS, Perfilieva E, Bjork-Eriksson T, Alborn AM, Nordborg C, Peterson DA, Gage FH. Neurogenesis in the adult human hippocampus. Nat Med. 1998;4:1313-7.

[119] Curtis MA, Kam M, Nannmark U, Anderson MF, Axell MZ, Wikkelso C, Holtas S, van Roon-Mom WM, BjorkEriksson T, Nordborg C, Frisen J, Dragunow M, Faull RL, Eriksson PS. Human neuroblasts migrate to the olfactory bulb via a lateral ventricular extension. Science. 2007;315:1243-9.
[120] Wang S, Scott BW, Wojtowicz JM. Heterogenous properties of dentate granule neurons in the adult rat. J Neurobiol. 2000;42:248-57.

[121] Treves A, Tashiro A, Witter MP, Moser EI. What is the mammalian dentate gyrus good for? Neuroscience. 2008;154:1155-72.

[122] Niibori Y, Yu TS, Epp JR, Akers KG, Josselyn SA, Frankland PW. Suppression of adult neurogenesis impairs population coding of similar contexts in hippocampal CA3 region. Nat Commun. 2012;3:1253.

[123] Park EH, Burghardt NS, Dvorak D, Hen R, Fenton AA. Experience-dependent regulation of dentate gyrus excitability by adult-born granule cells. J Neurosci. 2015; 35:11656-66.

[124] Akers KG, Martinez-Canabal A, Restivo L, Yiu AP, De Cristofaro A, Hsiang HL, Wheeler AL, Guskjolen A, Niibori Y, Shoji H, Ohira K, Richards BA, Miyakawa T, Josselyn SA, Frankland PW. Hippocampal neurogenesis regulates forgetting during adulthood and infancy. Science. 2014;344:598-602.

[125] Epp JR, Silva Mera R, Kohler S, Josselyn SA, Frankland $\mathrm{PW}$. Neurogenesis-mediated forgetting minimizes proactive interference. Nat Commun. 2016;7:10838.

[126] Frankland PW, Josselyn SA. Hippocampal neurogenesis and memory clearance. Neuropsychopharmacology. 2016;41:382-3.

[127] Andersen P, Bruland H, Kaada BR. Activation of the dentate area by septal stimulation. Acta Physiol Scand. 1961:51:17-28.

[128] Chandler JP, Crutcher KA. The septohippocampal projection in the rat: An electron microscopic horseradish peroxidase study. Neuroscience. 1983;10:685-96.

[129] Williams MR, DeSpenza Jr T, Li M, Gulledge AT, Luikart BW. Hyperactivity of newborn Pten knock-out neurons results from increased excitatory synaptic drive. J Neurosci. 2015;35:943-59.

[130] Castle MJ, Gershenson ZT, Giles AR, Holzbaur EL, Wolfe JH. Adeno-associated virus serotypes 1, 8, and 9 share conserved mechanisms for anterograde and retrograde axonal transport. Human Gene Therapy. 2014; 25:705-20.

[131] Zingg B, Chou XL, Zhang ZG, Mesik L, Liang F, Tao HW, Zhang LI. AAV-mediated anterograde transsynaptic tagging: Mapping corticocollicular input-defined neural pathways for defense behaviors. Neuron. 2017;93:33-47.

[132] Card JP, Enquist LW. Transneuronal circuit analysis with pseudorabies viruses. Curr Protoc Neurosci. 2014;68:1.5.1-39.

[133] Aston-Jones G, Chen S, Zhu Y, Oshinsky ML. A neural circuit for circadian regulation of arousal. Nat Neurosci. 2001;4:732-8 